\title{
Entre a fé e o fruto do conhecimento: o ensino religioso no Colégio Progresso Campineiro, Campinas-SP, (1900-1937)
}

\author{
Between faith and the fruit of knowledge: the religious education of \\ the Colégio Progresso Campineiro, Campinas-SP (1900 - 1937)
}

\author{
Priscila Kaufmann Corrêa $a^{* *}$
}

RESUMO

O presente trabalho fornece um panorama da pesquisa de mestrado, que procura compreender o ensino religioso no Colégio Progresso da cidade de Campinas (SP) no período de 1900 a 1937. O ensino religioso se mostra uma particularidade deste colégio, posto que, quando de sua fundação em 1900, pretendia-se oferecer um estabelecimento laico para o sexo feminino. O Colégio Progresso foi fundado pela iniciativa de cinco campineiros influentes na cidade e teria uma proposta diferente das demais escolas femininas, todas fora da cidade e de caráter confessional. $\mathrm{O}$ caráter religioso da escola, de cunho católico, ganhou força sob a direção de Dona Emília de Paiva Meira, a segunda diretora da escola, que ocupou o cargo de 1902 a 1937, quando faleceu.

Além de investigar o espírito religioso da diretora, a qual procurava inspirar professoras e alunas com seu exemplo, esta pesquisa procura compreender o ensino religioso como elemento da cultura desta escola (JULIA, 2001), tanto como um corpo disciplinar, quanto como um conjunto de práticas e crenças.

PALAVRAS-CHAVE: Educação feminina, Ensino religioso, Colégio
arquivo escolar.

\section{ABSTRACT}

This paper provides an overview of the research master's, which seeks to understand the religious education in Colégio Progresso da cidade de Campinas of Campinas (SP) in the period 1900 to 1937 . The religious education was a feature of this school since, when in its founding in 1900, was to offer a secular establishment for females. The College Progress was founded by the initiative of five influential Campineira in the city and have a proposal different from other women's schools, all outside the city of character and faith. The school's religious character of Catholic imprint, gained strength under the direction of Mrs. Emilia de Paiva Meira, the second director of the school, he held the post from 1902 to 1937 , when he died.

Besides investigating the religious spirit of the principal, which sought to inspire teachers and students with her example, this research seeks to understand the religious education as part of the culture of this school (JULIA, 2001), both as a disciplinary body, and as a set of practices and beliefs.

KEYWORDS: Female education; Religious education; Colégio Progresso; School culture; School archive; Campinas; Brazil.

Estudar o ensino religioso de uma instituição escolar específica em um determinado período pode parecer curioso, contudo, trata-se de uma instituição especial, na cidade de Campinas (SP), que este ano completará 109 anos. Os

\footnotetext{
Mestrado financiado com bolsa CAPES, realizado na Faculdade de Educação da Unicamp, sob orientação da Prof $^{\mathrm{a}}$. Dr ${ }^{\mathrm{a}}$. Maria do Carmo Martins.

** Mestranda em Educação pela Universidade Estadual de Campinas (Unicamp) / Brasil.
} 
primórdios da educação escolar apontam uma estreita relação entre escolarização e religião, não apenas pelos projetos educacionais de ordens religiosas (jesuítas), mas pelos seus resquícios que encontramos nas práticas no interior das instituições escolares (HAMILTON, 1989; JULIA, 2001).

Nesse sentido, o presente trabalho apresenta algumas considerações em torno de minha pesquisa de mestrado "Consciência reta: o ensino religioso e suas dimensões no Colégio Progresso Campineiro (1900-1037)”, que procura compreender o ensino religioso em suas diversas facetas no interior desta escola. A mesma foi fundada para ser uma instituição laica para o sexo feminino no início do século XX, porém o ensino religioso sempre se mostrou presente. As práticas religiosas foram intensificadas no colégio com a chegada da segunda diretora, Dona Emília de Paiva Meira, que assumiu seu cargo em 1902 e permaneceu à frente do estabelecimento até 1937.

A presença desta diretora se mostrou significativa para o colégio, marcando sua trajetória por mais de 100 anos. Uma das marcas de Dona Emília consistiu justamente no fortalecimento do ensino religioso de cunho católico, por meio de aulas e práticas que envolviam toda a comunidade escolar. Nesta perspectiva a pesquisa iniciada em 2008 procura compreender os desdobramentos do ensino religioso no interior da escola, sendo entendido como um importante elemento de sua cultura, que influencia todos os seus sujeitos (JULIA, 2001).

Além de analisar o ensino religioso no Colégio Progresso, é necessário apresentar os caminhos que levaram a este trabalho, que foi iniciado em 2004 com uma pesquisa de iniciação científica e que deu origem a um arquivo escolar, conhecido como "Memorial do Colégio Progresso". O levantamento e a organização deste acervo se mostram elementos facilitadores ao pesquisador, que busca exatamente os documentos de que precisa, sem a necessidade de consultar todos os materiais. Concomitantemente, este trabalho pretendeu também iniciar a sensibilização da comunidade escolar para a preservação de um patrimônio histórico da cidade.

\section{A organização do acervo histórico escolar}

Esta pesquisa é desenvolvida com base no acervo documental guardado 
pelo colégio, que possui uma grande diversidade de materiais, como livros de matrícula e chamadas, além de fotografias, correspondências, atividades de alunos. Todo este material foi levantado e parcialmente organizado no período de 2004 a 2008. O trabalho foi iniciado nesta escola em 2004 com a minha pesquisa de iniciação científica durante o curso de pedagogia, que resultou em meu trabalho de conclusão de curso, defendido em 2005. ${ }^{1}$ A investigação inicial acerca do ensino religioso desenvolveu-se paralelamente à organização dos documentos necessários à pesquisa, realizando seu levantamento e referenciamento.

A organização do acervo foi ampliada por meio de um projeto coordenado pelas professoras doutoras Maria do Carmo Martins e Heloísa Helena Pimenta Rocha, do Centro de Memória da Educação (CME), da Faculdade de Educação da Unicamp². O projeto contou com o financiamento pelo edital universal do CNPq e teve duração até 2007. O Colégio Progresso, à época mantido pelas Faculdades Integradas Metropolitanas de Campinas (Metrocamp) apoiou todo o trabalho, fornecendo materiais e um espaço específico para o acervo. Os documentos que se encontravam inicialmente na sacristia da capela foram transportados para o local que chegou a abrigar a casa da diretora. Neste espaço o acervo mudou de lugar duas vezes, permanecendo atualmente em uma sala isolada, mais adequada à sua preservação.

1 Este trabalho intitula-se "Decifra-me ou te devoro: Levantamento e Análise das Fontes sobre Ensino religioso do Colégio Progresso Campineiro na Primeira República (1900-1937)” e está disponível em: <http://www.fe.unicamp.br/servicos/centro_memoria/publicacoes.htm>.

2 O projeto, intitulado "Memórias da Educação escolar: cultura material e organização de acervos escolares", foi desenvolvido em duas escolas, sendo uma o próprio Colégio e a outra a Escola Estadual Orosimbo Maia, pela equipe coordenada pelas professoras doutoras Maria do Carmo Martins e Heloísa Helena Pimenta Rocha e com a orientação do professor Rogério Xavier Neves. Na escola estadual o trabalho de recuperação é bastante intensivo, com a organização do acervo e acondicionamento em móveis e pastas adquiridos pelo projeto, a digitalização da documentação, a elaboração de um banco de dados específico desta instituição para expor este material pela internet, além da reconstrução de sua história, que não possuía um registro ou uma investigação aprofundada até o momento. Nesta instituição a organização e a pesquisa do acervo contam com a participação das estudantes de pedagogia Bianca J. Caetano e Carla C. Tortorelli Bizzarro, sendo a digitalização realizada pela bolsista Rayane J. Aranha da Silva e o banco de dados foi construído pelo bolsista Diego Fernandes G. Martins.

Um curso de conservação e preservação de fotografias, baseado em um levantamento realizado nas duas escolas, foi realizado com a especialista Marli Marcondes, do Centro de Memória da Unicamp em maio de 2007. Após este curso foram adquiridos alguns materiais pelo CME para dar início à preservação destes acervos, que possuem sua especificidade.

Deste projeto resultaram diversos trabalhos, como os filmes "O Colégio" e "A Escola", do historiador e fotógrafo Alan Victor Pimenta, dois relatórios sobre a arquitetura das escolas e seu entorno, de autoria do arquiteto Rodrigo Martins Bryan e os relatórios de Iniciação científica das estudantes de pedagogia, além das apresentações do projeto em eventos no Brasil, na América Latina e na Europa. 
A equipe do CME contou com a colaboração do professor Rogério Xavier Neves para a criação de um organograma específico para o acervo. Em parceria com o Sistema de Arquivos da Unicamp (Siarq) foi criado um banco de dados para a catalogação dos documentos e a disponibilização destas informações para pesquisadores. Atualmente o banco de dados encontra-se em manutenção. A catalogação segue as normas de arquivística ISAD (G) e ISAAR, a fim de padronizar as informações sobre a documentação, em consonância com as regras internacionalmente estabelecidas.

Todo o trabalho no acervo contou ainda com a colaboração da antiga diretora do Colégio Progresso, Maria Lúcia Canecchio Ribeiro, e com a coordenação da professora doutora Lilian Alvisi, além de muitos alunos dos cursos da Metrocamp, que atuaram como voluntários em troca de descontos nas mensalidades. Trabalhei como funcionária do acervo no período de 2006 a 2008 e ao longo destes anos foram realizadas atividades com algumas turmas de alunos do Colégio Progresso. Nestas atividades foi apresentada a história da escola e da cidade utilizando-se do material do acervo, além de uma visita ao próprio.

As atividades foram interrompidas com as mudanças na administração do colégio e da faculdade. O antigo sócio da Metrocamp tornou-se proprietário do Colégio Progresso e entre as primeiras medidas que adotou estava a suspensão das atividades do Memorial. Até o momento o acervo encontra-se no mesmo local e sua organização não foi desfeita. Os documentos foram disponibilizados para esta pesquisa, porém as demais atividades permanecem interrompidas desde junho de 2008. Diante deste impasse, espera-se que com esta pesquisa se possa sensibilizar a nova administração da escola no sentido de retomar as atividades de conservação e catalogação do acervo.

\section{O Colégio Progresso Campineiro}

Esta instituição escolar foi fundada em 1900 por Orosimbo Maia, Arthur Leite de Barros, Antonio Álvaro de Souza Camargo, Joaquim Álvaro de Souza Camargo e Luiz de Campos Salles, senhores bastante ilustres e influentes econômica e politicamente na cidade de Campinas. Sua intenção era criar uma instituição de ensino laica que atendesse suas filhas, sobrinhas e afilhadas, 
moças distintas que seriam as futuras mães e esposas dos membros da elite. Para exercerem seu papel na sociedade, careciam de instrução, que fornecesse conhecimentos de artes, música e línguas, mas diferenciando-se de outras propostas de educação feminina pelo ensino de matemática, ciências, química e física. O Colégio Florence, de caráter laico, possuía uma proposta similar a esta desejada pelos fundadores do Colégio Progresso, porém teve suas atividades encerradas em 1889, após as epidemias de febre amarela que dizimaram grande parte da população campineira.

Inspirados pela filosofia positivista européia, os fundadores do Colégio decidiram nomeá-lo de Progresso, nome que carrega consigo os ideais desta filosofia e dos próprios fundadores, cidadãos que desejavam uma educação diferenciada para as moças da elite, para que estas formassem os futuros cidadãos e líderes da nação que recentemente se proclamara republicana (UHLE, 1998).

O Colégio foi inaugurado na Chácara Guanabara em 1900, sendo contada a lenda que a instituição foi dada de presente pelo pai Orosimbo Maia à sua filha, Odila Maia, no dia 8 de outubro, seu aniversário. Este gesto simbolizaria o valor dado à educação das meninas, que não precisariam mais sair da cidade de Campinas para freqüentarem uma escola, que atenderia esta elite a partir daquele momento. O mobiliário escolar foi comprado de um Colégio Progresso em São Paulo, que estava encerrando suas atividades, e a sua diretora, Dona Anna von Maleszewska, senhora austríaca formada pelas universidades de Kiel, na Alemanha, e Nancy, na França, foi chamada a dirigir o novo estabelecimento em Campinas.

Uma diretora que tivesse sua formação na Europa foi vista como uma característica positiva, mas Dona Anna não permaneceu por muito tempo no cargo, sendo mandada embora em 1902 (UHLE, 1998). Os motivos para a sua dispensa não são muito claros, mas alguns registros em um caderno dos primeiros anos do Colégio Progresso indicam que a mesma talvez não fosse tão rigorosa em seu cargo quanto seria o esperado.

Dona Emília de Paiva Meira foi a pessoa escolhida por Orosimbo Maia para ocupar a direção do Colégio. Nascida na Parnaíba, Piauí, em 1872, a filha do conselheiro João Florentino Meira de Vasconcellos foi indicada pelo irmão ao amigo Orosimbo Maia, que insistiu para que ela assumisse a direção da 
escola.

Assim, Dona Emília acabou assumindo a direção da instituição, permanecendo à sua frente por 35 anos. O período de 1902 a 1937 foi marcante para a trajetória do Colégio Progresso, pois neste período a nova diretora ganhou destaque e prestígio por sua dedicação à obra educacional, sendo a escola reconhecida pelo seu ensino. Neste período o colégio foi transferido de edifício por três vezes, sendo sua sede final à Avenida Júlio de Mesquita, em um prédio imponente idealizado por ela, junto com outros arquitetos.

A propriedade do Colégio Progresso foi passada para Dona Emília em 1913, quando a sociedade dos fundadores se desfez. A diretora continuou contando com o apoio de Orosimbo Maia nas suas obras, inclusive na construção do prédio definitivo do colégio, assim como em outras questões financeiras.

Em 1924, Dona Emília fundou o Colégio Progresso de Araraquara, cuja direção ficou nas mãos de Dona Julie Villac, que fora aluna e professora do Colégio em Campinas e logo se tornara seu braço direito. Em 1928 foi criada a Escola Normal anexa ao Colégio Progresso Campineiro, permitindo a formação profissional das moças em uma carreira considerada digna para o sexo feminino.

Neste mesmo ano, Dona Emília criou a Sociedade Brasileira de Educação e Instrução de Meninas, que manteria os dois colégios com pessoas de confiança da diretora. Nessa Sociedade podiam ingressar apenas mulheres "católicas, solteiras e de moral ilibada", assegurando assim os fins educacionais e sem fins lucrativos dos dois estabelecimentos, mesmo após sua morte. Em seu testamento ela também ressalta a importância desta questão, exigindo que a proposta do colégio fosse mantida, podendo ser transferido para os padres salesianos, caso os fins educacionais não fossem assegurados.

A tônica religiosa emerge, portanto, com a presença de Dona Emília no colégio, uma pessoa muito querida e respeitada pelas alunas, professoras, pais e demais setores da sociedade. A sua dedicação à escola, que acabou se tornando a sua família, posto que ela não constituíra uma, rendeu-lhe muita admiração, sendo lembrada por ex-alunas como uma senhora abnegada e virtuosa, que inspirava nas meninas a obediência e a prudência.

A religiosidade da diretora influenciou muito a escola, que ganhou uma 
capela e associações religiosas, como a Pia União das Filhas de Maria, a Congregação dos Santos Anjos e a Liga Eucarística. Estas associações, dirigidas por padres, eram compostas por meninas que mereciam participar das mesmas por seu esforço para serem "boas moças". Nas reuniões destas associações, o padre-diretor exortava as meninas a uma boa conduta e à obediência.

Pela documentação encontrada no colégio, observa-se que a religião estava impregnada no ambiente escolar, inspirando as alunas à moralidade e à obediência, sem que houvesse uma disciplina específica de ensino religioso. Assim, a religião penetrava na escola com o objetivo de moralizar as moças, porém sem se configurar como uma disciplina lecionada especificamente em sala de aula.

Quando Dona Emília faleceu, em 1937, a forma encontrada para homenageá-la foi conseguir uma autorização da prefeitura da cidade para erguer seu túmulo ao lado da capela. Seu falecimento significou um choque para a escola, mas que conseguiu manter por muitos anos o espírito religioso e abnegado da primeira diretora na continuidade da obra que ela auxiliou a erguer.

A Sociedade Brasileira de Educação e Instrução de Meninas deu continuidade ao trabalho idealizado por Dona Emília, tendo à sua frente Dona Julie Villac e Dona Flávia Campos da Paz, que tinham trabalhado ao seu lado e foram de sua confiança. Dona Julie esteve à frente da Sociedade até 1982, quando esta se tornou a Sociedade Brasileira de Educação e Instrução. A mantenedora continuou funcionando nos mesmos moldes estabelecidos por Dona Emília em seu testamento, porém, em 2002, precisou encerrar suas atividades devido a dificuldades financeiras. Diante da possibilidade do colégio fechar suas portas, os alunos se manifestaram nas ruas do Cambuí exigindo que a escola continuasse a funcionar. A mantenedora recebeu diversas propostas de grupos educacionais e acabou passando a manutenção do Colégio Progresso para a Metrocamp. Em 2008 a escola sofreu novas mudanças e passou a ter um novo proprietário, como foi indicado anteriormente.

Este breve histórico do Colégio Progresso permite compreender alguns aspectos de sua trajetória, sempre atendendo a uma elite, não apenas campineira, mas da região, oferecendo um ensino diferenciado e sofisticado. Por muitos anos as práticas religiosas se fizeram presentes na escola, porém 
restringindo-se mais ao espaço da capela. Cabe agora apresentar alguns elementos deste ensino religioso no interior da escola.

\section{O ensino religioso e suas dimensões}

O trabalho iniciado durante a graduação permitiu identificar as associações religiosas como um espaço privilegiado do ensino religioso na escola. As associações religiosas, com seu estímulo ao bom comportamento e à obediência, se mostraram um espaço propício para a formação religiosa das alunas do Colégio Progresso. Nessa escola foram organizadas quatro destas associações : a Pia União das Filhas de Maria, a Congregação do Santos Anjos, a Liga Eucarística e o Oratório Festivo Dom Bosco. Essas Associações abrigavam as moças que realmente mereciam participar delas, reunindo-as em determinados dias do mês para ouvirem uma pregação do padre-diretor. As finalidades de cada congregação eram relativamente diferentes, privilegiando algumas questões religiosas, mais do que outras. Entretanto, em todas elas encontra-se um discurso que visava incutir nas alunas a obediência, a resignação, a pureza e a caridade. O padre, no altar, procurava exortar as meninas e moças a seguirem pelo bom caminho, utilizando-se da religião para justificar tal postura.

Os materiais encontrados até então indicavam que estas associações seriam um momento relevante para a formação religiosa, com seu estímulo à competição entre as alunas, que deveriam se esmerar para serem virtuosas e obedientes. As associações religiosas, porém, tinham um alcance restrito às alunas associadas e as suas atividades não aconteciam com muita frequência, não havendo muita regularidade nas reuniões. Isso significa que o ensino religioso não poderia se restringir a estas associações. O trabalho no arquivo e a incorporação de documentos do "arquivo morto" da secretaria permitiram identificar que o ensino religioso esteve presente como um corpo disciplinar no currículo da escola, além de compor a rotina da mesma por meio de diferentes práticas estabelecidas por regulamentos.

O Colégio Progresso, desde os seus primeiros anos, procurou divulgar seu curso e sua proposta de ensino por meio de prospectos, pequenas brochuras que podiam apresentar as matérias de ensino, suas finalidades, além das 
mensalidades e outras informações sobre a organização interna da escola, como a disciplina e o calendário escolar. No acervo da escola existe uma grande diversidade destes materiais, que abrangem o período de 1900 até os anos de 1950. Também existem prospectos de outras instituições, notadamente aquelas dirigidas por Dona Anna Von Maleszewska e Dona Emília Meira antes de trabalharem em Campinas. Por estes materiais, que datam da década de 1890, é possível perceber que as propostas iniciais do Colégio Progresso se baseavam nas experiências anteriores das diretoras. Dona Emília chegou a dirigir um Colégio Progresso em Curitiba, inspirada pela sua formação no Colégio Progresso do Rio de Janeiro, uma instituição dirigida pela norte-americana Miss Eleanor Leslie Hentz e que se caracterizava pelo ensino diferenciado para meninas (HAIDAR, 1972; p. 241). Nessa instituição as meninas aprendiam as mais diferentes matérias, com destaque para as aulas de geografia, nas quais desenhavam mapas com rapidez e precisão.

A experiência escolar inspirou Dona Emília na organização do seu colégio em Curitiba, porém a diretora precisou sair do estado por motivos desconhecidos e acabou indo para Campinas, onde encontrou a possibilidade de reiniciar seu trabalho educacional. Sua chegada ao colégio acarretou mudanças na organização dos horários e dos cursos da escola, que passou a ter um curso primário de $1^{\mathrm{o}}$ e $2^{\mathrm{O}}$ graus, um curso secundário e um curso de artes ou complementar. Nesses prospectos eram elencadas as "matérias de ensino" de cada curso.

Os materiais que se referem ao período investigado permitiram identificar o ensino religioso em quatro matérias diferentes: doutrina cristã, catecismo, história sagrada e religião, restritas ao curso primário, tanto do $1^{\mathrm{o}}$, quanto do $2^{\mathrm{o}}$ grau. No ano de 1900 e 1901 havia a matéria de doutrina cristã, logo suprimida em 1902 e substituída pela disciplina de catecismo. A partir de 1909 a matéria de catecismo ficou restrita ao curso primário de $1^{0}$ grau, junto com a de história sagrada. A partir de 1918, quando o Colégio Progresso se encontrava em seu prédio definitivo, o catecismo foi substituído pela matéria de religião e voltou a ser lecionado nos dois graus do curso primário. O ensino religioso aparentemente não entrava na grade curricular no curso secundário. Pelo fato destas matérias se restringirem ao curso primário, elas provavelmente compunham a formação religiosa necessária à realização da Primeira 
Comunhão, que acontecia todos os anos no próprio colégio.

Se as turmas de alunas e as matérias para cada uma delas estavam bem definida nos prospectos, a análise de livros de notas e faltas do período de 1903 a 1924 permitiu identificar que a organização das turmas de uma forma diferente daquela colocada nesses materiais. Nestas brochuras, com tabelas e notas manuscritas a lápis e bico de pena, as turmas de alunas eram divididas em "pequenas", "médias", "grandes" ou "maiores", chegando a existir um grupo de "intermediárias", quando o número de alunas se tornou muito numeroso. As matérias para todas estas turmas eram muito semelhantes, inclusive a de religião, obrigatória a todas, já que se recebia nota para ela.

A partir da década de 1910, os prospectos indicam a possibilidade das alunas que terminavam o curso secundário prestarem exames no ginásio oficial para receberem um certificado. A preocupação com uma certificação legalmente reconhecida torna-se mais evidente nesta época. Entretanto, apenas em 1925, com a Reforma João Luiz Alves, estabelecida pelo decreto 16.782-A, foi possível instalar juntas examinadoras no próprio colégio, que neste momento já possuía um edifício próprio, adequado às exigências educacionais. Para tal fim, a escola precisou reorganizar seus cursos, principalmente o secundário, que era avaliado perante as juntas. Com isso, a matéria de religião deixou de figurar entre os registros das atas dos exames, já que ela não constava dos programas de ensino.

O reconhecimento do governo federal se mostrou necessário ao colégio, a fim de legitimar seu ensino perante a sociedade. O remodelamento dos cursos em função das exigências legais não significou, contudo, a supressão do ensino religioso na escola, posto que outros materiais indicam a presença de religiosos e continuidade de tais práticas.

Desde a fundação da escola existia um padre, que lecionava religião para as alunas e as preparava para a Primeira Comunhão. Nos primeiros anos da escola as alunas assistiam a missa aos domingos no colégio do Liceu Salesiano, uma instituição próxima do primeiro prédio do Colégio Progresso. Uma capela própria foi criada apenas em 1908, no galpão de ginástica do Palacete Anhumas, segundo espaço ocupado pela escola. No mesmo ano, porém, a instituição escolar precisou ser transferida para um novo prédio, posto que a Diocese de Campinas foi inaugurada no palacete. A capela foi instalada no novo prédio da escola, que ocupou o edifício em que ficava o Colégio Florence, que foi 
transferido para Jundiaí, em 1889, devido às epidemias de febre amarela que assolaram a cidade (RIBEIRO, 1996). A capela tinha São Luiz de Gonzaga como padroeiro, que também é padroeiro da juventude. Esta capela também foi criada no prédio definitivo da escola, inaugurado, em 1917, na Avenida Júlio de Mesquita.

Esse prédio se localiza no atual bairro Cambuí, uma área nobre da cidade. O edifício foi idealizado para ser uma escola, com laboratórios, pátios, salas de aula, dormitórios e refeitório, além da capela. Trata-se de um espaço completo para os cultos, com o altar de mármore branco, sacristia e confessionário. Neste local eram celebradas as missas diárias e realizadas as Primeiras Comunhões e comunhões. O capelão era indicado pela Diocese de Campinas e para ocasiões especiais Dona Emília precisava preencher um requerimento. Estes protocolos à Diocese também foram encontrados no acervo da escola, indicando a preocupação em respeitar as normas estabelecidas pela Igreja para a realização dos cultos nesse recinto.

A capela se mostrava um espaço reservado para os cultos católicos e deveria ser frequentado por todos na escola. Muitas professoras moravam na escola, assim como a diretora e os funcionários responsáveis pela manutenção, no sentido de assegurar a disciplina e a ordem no internato. Um regulamento contendo os horários de todo o pessoal da escola aponta que eram realizadas missas todos os dias, com a possibilidade dos fiéis se confessarem e comungarem. Visitas ao Santíssimo Sacramento eram recomendadas às professoras neste documento, além das orações antes das refeições e de dormir. O cotidiano do colégio era, pois, permeado por práticas religiosas, fornecendo, por vezes, um tom diferenciado à rotina, como no caso das Primeiras Comunhões. Além destes eventos, antes das férias de julho, eram realizados retiros espirituais para as Filhas de Maria e, no final do ano, havia o retiro para as alunas e depois para as senhoras católicas. Nesses últimos, as alunas permaneciam em silencio e deveriam meditar sobre suas ações, fazendo um exame de consciência. Para estas ocasiões era chamado um padre que fazia algumas pregações pertinentes a este momento de reflexão.

Estas práticas deveriam ser incorporadas pelas alunas para serem realizadas ao longo de suas vidas, em uma formação cristã em consonância com os preceitos da Igreja. A capela na escola, sempre com um religioso para atender 
a todos e celebrar os cultos, assegurava um espaço para a Igreja na escola. A própria Igreja reconhecia a importância do trabalho do Colégio Progresso e apoiava sua diretora. A formação das mulheres da elite, futuras esposas e mães dos futuros cidadãos, deveriam oferecer um exemplo de conduta moral para a sociedade e seus filhos, nos moldes da religião católica. Neste sentido, a formação religiosa se mostrava um elemento interessante para a formação moral das alunas, as quais deveriam se mostrar virtuosas e obedientes.

A inserção destas práticas religiosas no cotidiano da escola se deve à sua valorização pela própria diretor. Dona Emília de Paiva Meira se mostrava uma senhora muito devota e, em diversos registros de ex-alunas e professoras que a conheceram emerge, seu espírito religioso. Inclusive, a própria conhecia muitos religiosos e se comunicava com eles por correspondências. No acervo existem 66 cartas de diferentes religiosos, sendo que muitas delas se referem a um momento particularmente importante da vida de Dona Emília. Em 1919, ela decidiu ingressar na Ordem Terceira de São Domingos Gusmão, um grupo formado por um padre diretor e católicos leigos que buscam se aperfeiçoar espiritualmente, semelhante às associações religiosas do colégio. $\mathrm{O}$ ingresso na Ordem Terceira era realizado em duas etapas. Primeiramente o aspirante "tomava o hábito" e, no período de um ano, procurava aperfeiçoar-se para chegar o momento de "fazer profissão". Quando chegado, o aspirante tornava-se postulante e escolhia o nome de um santo para ser identificado no grupo e ter como exemplo. Dona Emília fez profissão em 1920 sob o nome de Santa Catarina de Siena, a padroeira da Ordem.

Por tal motivo, ao longo do ano de 1919, Dona Emília Meira se comunicou com diversos religiosos, compartilhando suas dúvidas e inseguranças com relação à sua fé. Nas cartas destes religiosos emerge um conselho constante de abandono à providência divina. A diretora deveria confiar inteiramente nos desígnios de Deus, que saberia conduzi-la pelo melhor caminho, mesmo que este não fosse o mais simples.

Ela procurou seguir este conselho à risca e, com sua postura virtuosa e até resignada, conseguiu conquistar o respeito e a admiração daqueles que a conheceram. Esta forte inclinação religiosa, contudo, se mostrou um elemento de sua personalidade interessante para sua circulação no meio público. Dona Emília não se casou nem teve filhos, fugindo dos padrões femininos da época. 
Como proprietária de dois colégios ela tinha muitas atribuições e responsabilidades, que a lançaram ao meio público, predominantemente masculino. O seu espírito religioso fornecia ares mais "femininos" à sua personalidade e facilitava sua circulação pelo espaço público, conquistando o respeito de todos. Com estas características de certa "fragilidade" apropriada para a mulher, desempenhou um importante papel na sociedade e deixou um legado para ela, sendo por muitos anos lembrada.

\section{Considerações finais}

Esta pesquisa se encontra em andamento e por esta razão existem ainda questões a serem aprofundadas. O panorama fornecido por este trabalho indica que mesmo um colégio laico do início do século XX não abriu mão do ensino religioso quando se tratou da formação religiosa das filhas da elite, futuras mães e esposas de uma nação recém-proclamada republicana. Sua honra e virtude estavam, pois, em jogo e a formação escolar poderia fornecer não apenas os conhecimentos literários e científicos de sua época, mas uma sólida base moral e religiosa.

O colégio que iniciara sua trajetória de forma improvisada em uma chácara, conquistou fama e seu espaço na sociedade, precisando ser reconhecido também pelo governo federal. O Colégio Progresso buscou, assim, adequar-se à legislação do ensino, tornando-se um estabelecimento legalmente reconhecido na cidade. Esta adequação à lei não impediu que alguns elementos da proposta pedagógica inicial fossem abandonados, como no caso do ensino religioso. Este permaneceu na escola e tinha seu espaço assegurado e envolvia todos os sujeitos da instituição. A valorização do aspecto religioso no colégio se deveu à diretora, que considerava a religião um elemento importante para a sua vida e também para a formação de suas alunas.

O Colégio Progresso, mesmo com estas características religiosas tão evidentes, continuava sendo considerado uma instituição laica, já que não pertencia a nenhuma ordem religiosa. $\mathrm{O}$ ensino religioso, porém, era um fator que auxiliou a escola a se legitimar perante a sociedade e conseguir seu apoio, assim como da Igreja também. Observar estes meandros da escolarização no passado ajuda a compreender como esta instituição se tornou legítima e 
praticamente imprescindível na sociedade contemporânea, tanto para meninas, quanto para meninos.

\section{Bibliografia:}

BITTENCOURT, Águeda Bernadette. Educação escolar: Um Compromisso da Família com a Igreja. IN: ALMEIDA, Ana Maria F.; NOGUEIRA, Maria Alice (orgs.). A escolarização das elites: um panorama internacional da pesquisa, Petrópolis: Vozes, 2002.

CHERVEL, André. "História das disciplinas escolares: reflexões sobre um campo de pesquisa”. In: Teoria \& Educação, n. 2, Porto Alegre, 1990. pp. 177229.

CORRÊA, Priscila Kaufmann. Decifra-me ou te devoro: Levantamento e Análise das Fontes sobre Ensino religioso do Colégio Progresso Campineiro na Primeira República (19oo - 1937). Trabalho de Conclusão de Curso, Unicamp, 2005. Disponível em:

<http://www.fe.unicamp.br/servicos/centro_memoria/publicacoes.htm>.

HAIDAR, Maria de Lourdes M. O ensino secundário no Império brasileiro. São Paulo: EDUSP-Grijalbo, 1972.

JULIA, Dominique. A cultura escolar como objeto histórico. IN: Revista Brasileira de História da Educação. VI, jan./jun. 2001, pp. 9-43.

MORASSUTI, Daniela. Colégio Progresso Campineiro: Os primeiros cinqüenta Anos, Trabalho de Conclusão de Curso: Unicamp, 1997.

NASCIMENTO, Therezinha A. Q. R. et all. Memórias da Educação:Campinas (1850 - 1960). Campinas (SP): Editora da Unicamp, 1999.

NAGLE, Jorge. Educação e Sociedade na Primeira República. São Paulo: EPU, 1974.

RIBEIRO, Arilda I. M. A Educação feminina durante o Século XIX: o Colégio Florence de Campinas (1863-1889). Campinas: Ed. da Unicamp, 1996.

UHLE, Águeda Bernadette B. Orosimbo Maia: Cultura e Política no Final do Século XIX. IN: Pró-Posições, vol. 9 nº 1 [25], Campinas, março de 1998.

VINCENT, Guy; LAHIRE, Bernard; THIN, Daniel. Sobre a história e a teoria da. forma escolar. IN: Educação em Revista, Belo Horizonte, n. 33, pp. 7-47, jun. 2001.

Colaboração recebida em 31/03/2009 e aprovada em 17/06/2009. 